\title{
Overlooked and Under-Studied: A Review of Evidence-Based Enrichment in Varanidae
}

\author{
Darcy Howard *(D) and Marianne Sarah Freeman (D)
}

check for updates

Citation: Howard, D.; Freeman, M.S. Overlooked and Under-Studied: A

Review of Evidence-Based

Enrichment in Varanidae. J. Zool. Bot. Gard. 2022, 3, 32-43. https:// doi.org/10.3390/jzbg3010003

Academic Editors: Kris Descovich, Caralyn Kemp and Jessica Rendle

Received: 27 October 2021

Accepted: 11 January 2022

Published: 17 January 2022

Publisher's Note: MDPI stays neutral with regard to jurisdictional claims in published maps and institutional affiliations.

Copyright: () 2022 by the authors. Licensee MDPI, Basel, Switzerland. This article is an open access article distributed under the terms and conditions of the Creative Commons Attribution (CC BY) license (https:/ / creativecommons.org/licenses/by/ $4.0 /)$.

\author{
Animal Health and Welfare Research Centre, University Centre Sparsholt, Winchester SO21 2NF, UK; \\ Marianne.freeman@sparsholt.ac.uk \\ * Correspondence: darcy.b.howard@gmail.com
}

\begin{abstract}
Enrichment has become a key aspect of captive husbandry practices as a means of improving animal welfare by increasing environmental stimuli. However, the enrichment methods that are most effective varies both between and within species, and thus evaluation underpins successful enrichment programs. Enrichment methods are typically based upon previously reported successes and those primarily with mammals, with one of the main goals of enrichment research being to facilitate predictions about which methods may be most effective for a particular species. Yet, despite growing evidence that enrichment is beneficial for reptiles, there is limited research on enrichment for Varanidae, a group of lizards known as monitor lizards. As a result, it can be difficult for keepers to implement effective enrichment programs as time is a large limiting factor. In order for appropriate and novel enrichment methods to be created, it is necessary to understand a species' natural ecology, abilities, and how they perceive the world around them. This is more difficult for non-mammalian species as the human-centered lens can be a hinderance, and thus reptile enrichment research is slow and lagging behind that of higher vertebrates. This review discusses the physiological, cognitive, and behavioral abilities of Varanidae to suggest enrichment methods that may be most effective.
\end{abstract}

Keywords: captive; reptile; welfare; cognition; play

\section{Introduction}

Over the course of the last century, zoos have been transformed from menageries to institutions rooted in science. Long considered the father of zoo biology, Hediger first recognized the inadequacies of the zoo environment in 1950 and emphasized the need to promote the well-being of captive animals [1]. This can be achieved by providing captive animals with opportunities that allow them to display their behavioral capabilities, which was the goal of Markowitz, one that he termed 'behavioral engineering' in the 1970s [2]. Originally based on Skinner's theory of operant conditioning, it has developed to become what we know today as 'environmental enrichment' [3]. Now, over 40 years later, environmental enrichment has become standard practice in the management of captive animals [4]. The focus in enrichment research has moved from the need to provide enhancements in husbandry to how they can be rigorously assessed in order to monitor and improve welfare [5]. Despite the attention this field of zoo science has received, there is still the general opinion that enrichment is a supplementary aspect of care and not integral to the daily husbandry [5,6]. By definition, environmental enrichment is a principle of husbandry that aims to provide stimuli to improve animal care and thus mental and physical wellbeing [7]. Even by this definition it is regarded as extra to standard animal care. What can be agreed upon is that enrichment can be classified into five categories: social, physical, nutritional, occupational, and sensory [8]. Enrichment programs should aim to provide captive animals with enrichment methods from each category, rather than just one [9,10], to improve animal welfare [3] and promote the natural phenotype of their wild counterparts [11]. This is achieved by meeting goals such as increasing activity levels, 
natural/species-specific behaviors, choice and control, and behavioral diversity [12], as well as reducing the prevalence, or onset, of stereotypic or abnormal behaviors [13]. As has been consistently demonstrated, the extent of zoo research markedly varies across taxa [14,15], and this pattern holds constant for enrichment. A Web of Science search yielded over 1053 and 1256 publications with the terms 'enrichment mammals' and 'enrichment birds', respectively, and yet provided only 143 results for 'enrichment reptiles'. Thus, despite enrichment now being one of the key concepts in captive animal management [16], there are still knowledge gaps, and the lack of progress within non-avian reptiles (reptiles from this point forth) is striking [17]. A growing body of evidence suggests that one group of reptiles, the varanids, have high cognitive abilities and as such understanding how to meet the motivational needs of such a group of species is imperative to improving welfare standards in their care.

\section{Reptile Enrichment: What Do We Know?}

\subsection{Left in the Cold}

Within the scientific literature, a strong mammal-centric bias is prominent, with a scarcity of studies regarding reptile enrichment [12,14,18-20]. This may be in part due to the long-held misconception that reptiles are stoic, highly adaptable, and tolerant to suboptimal conditions [21], as well as too neurologically simple to suffer [22,23] and thus not requiring enrichment. Where enrichment is utilized, structural or habitat design-based enrichment was the most employed provision for reptiles within U.S. collections, with an average of $86 \%$ of holders reporting this provision across all the reptile taxa [17]. This reflects the notion that reptile behavior and cognition tends to be less well-understood compared to that of higher vertebrates [24]. With current understanding being heavily influenced by mammalian-centric paradigms [25], this makes them a low priority for enrichment provision [19]. Enrichment techniques that cater for the animals learning and social functions were reported to be much less utilized by collections [17]. As a result, current reptile husbandry is clearly less than ideal yet deemed acceptable [23].

\subsection{Do Reptiles Benefit?}

Despite the attention bias, this is a developing field (Figure 1), and the studies that have been published in peer-reviewed journals support the notion that reptiles benefit from enrichment [21,26-31] and that it is in fact essential [32]. Evidence for enrichment as a beneficial practice with reptiles is documented through an increase in natural behaviors and relaxed postures under structural enriched environments [33,34]. Additionally, the use of chemosensory enrichment (scent of conspecifics, based upon the species natural ecology) significantly $(p<0.001)$ reduced the occurrence of abnormal behavior (escape attempts) in wild-caught brown wall lizards (Podarcis liolepis) by 38\% [27]. Similarly, the use of fishscented enrichment cups resulted in a reduction in escape behaviors of aquarium-housed, freshwater turtles (Trachemys scripta and Pseudemys concinna), although there was an increase in aggression, which demonstrates the need to assess the efficacy of any new techniques before implementation [35]. When offered multiple forms of enrichment, leopard geckos (Eublepharis macularius) interacted with all forms and, in particular, to a feeding puzzle and to structural enrichment placed under a heat source [31]. The alternative forms, sensory (mirror and olfactory) and novel object enrichment, elicited less engagement; however, this highlights that the enrichment should be species-specific and biologically or ecologically relevant. In addition to simply documenting a difference in behavior, when given choice (and thus some level of control), corn snakes (Pantherophis guttatus) displayed more time occupying structurally enriched enclosures over standard housing [34]. Clearly, reptiles respond to, and benefit from, the provision of enrichment. 


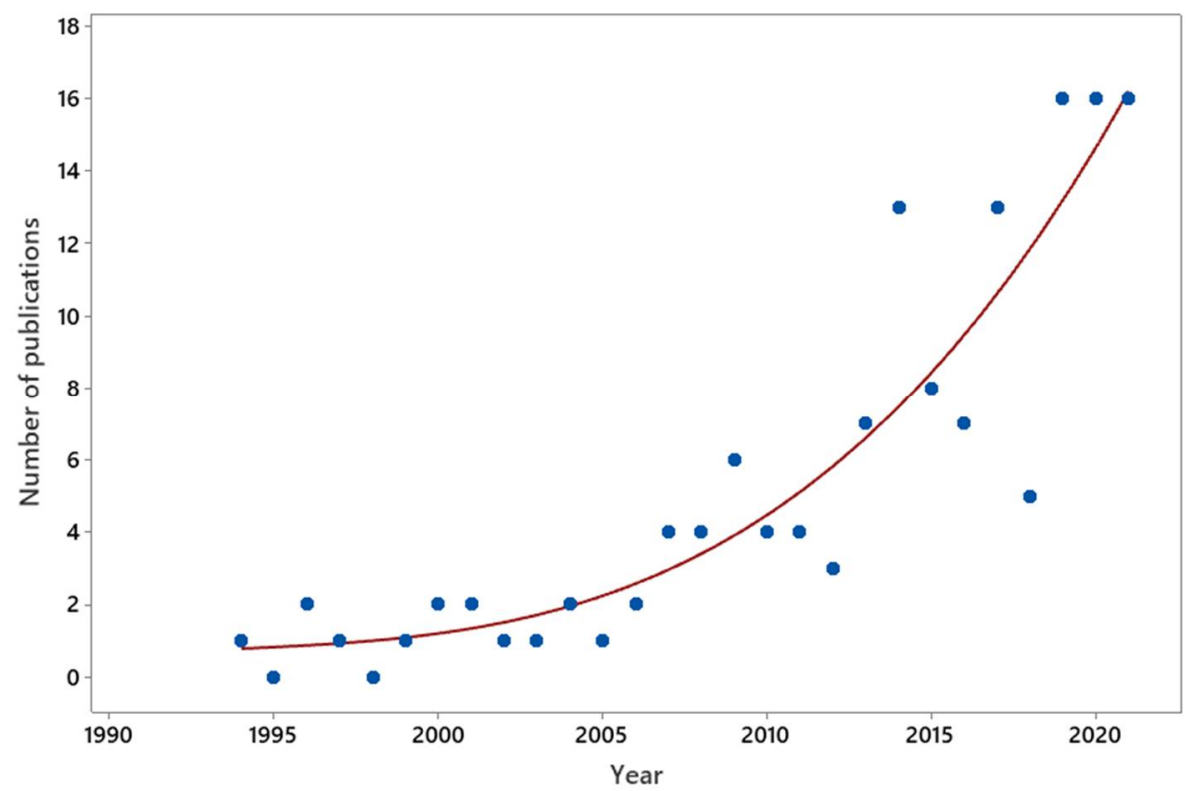

Figure 1. Number of publications using the terms 'reptile enrichment' from Web of Science over the past 30 years, as of October 2021.

Many enrichment studies have been carried out with relatively small sample sizes, often representing case studies of a few individuals. While large sample sizes are important for generalizability to the wider population as a means of predicting the most effective enrichment methods [36], there is also value in studies with small sample sizes [37,38], typically true of zoos [18]. While different complexities in enclosure design [39], confounding factors of sex, age [27], and individuality and the measures used to evaluate the enrichment [40] can lead to issues in generalization of the design, enrichment studies, in many cases, require an individual approach [41,42]. Differing past experiences, temperament, genetics, and coping mechanisms may lead to different preferences, while some individuals may, for example, choose tactile stimulation, others may choose food rewards [43]. The individual approach can also aid enrichment designs for individuals with additional needs [29]. However, for wider application, well designed studies with robust samples sizes are still needed to improve internal validity and ensure any changes are due to the design and not simply chance or impacted by keeper interactions and/or social learning from other individuals when housed together [44]. Thus, both small and large sample sizes are valuable and necessary in advancing reptile enrichment practices.

Furthermore, in addition to improving the welfare of captive individuals, advancements in reptile enrichment may benefit reptile conservation strategies, such as headstarting and translocation, by better preparing animals for wild challenges [45]. This may be particularly true of cognitive enrichment, which may take the form of a challenging puzzle or mentally challenging exploration, or involve training to help the individual cope with challenges and learn new species-specific behaviors [4,46]. Cognitive enrichment has been much less studied in reptiles; however, enrichment itself may help improve the cognitive function of all animals. Thus far, the effects of enrichment on translocation success have had mixed results. DeGregorio [47] found no effect of enrichment on translocation success of ratsnakes (Pantherophis obsoletus), and there was a negative correlation of success with time spent in captivity. Conversely, captive common watersnakes (Nerodia sipedon sipedon) had an equal rate of survival to that of the wild snakes [48]. This suggests that, while structural enrichment may not improve natural survival traits, enrichment that encourages or helps in learning the processes of natural foraging would be beneficial for maintaining natural behavioral traits. In addition, there are no studies investigating the effects of antipredator training in captive raised and released reptiles (although there are cases of toxin avoidance training in wild reptiles (see later)). Indeed, in painted turtles (Chrysemys picta), early life 
experience is vital to the development of successful navigation [49]. Training to improve navigation, predator recognition, prey location, and foraging training mentally stimulates the animal while providing the tools to improve survival [45], and this should be given more consideration in reptile husbandry going forward. More so, regardless of their level of sociality, no social enrichment studies in the reptilian taxa have been explored. Furthermore, there may exist social stages within the reptilian lifecycle; thus, an understanding of how sociality acts on their learning would be beneficial for optimal captive care [50] and possibly even conservation strategies.

\subsection{The Necessity of Evaluation}

The value of evidence-based enrichment and the need to broaden the research to a wider range of taxa, such as that of reptiles, is appreciated among zoo professionals [5]. This is particularly the case because keeper perceptions alone may not always be accurate, and personal expectations or lack of time to fully observe the animals can impact judgment. Mehrkam and Dorey [51] found that keepers were least accurate when predicting the preferred enrichment for a reptile (eastern indigo snake (Drymarchon couperi)) compared to other taxa. Aside from simply establishing preference, the effectiveness of an enrichment method to meet the required goals must be subjected to empirical evaluation before they can be definitively considered to be 'enriching' [10]. Januszczak et al. [39] found that using an enrichment device that was designed to present 10 live crickets (Gryllus spp.) to treerunner lizards (Plica plica) randomly over 40 min was less effective than the commonly used and simpler method of scatter-feeding. Additionally, despite basing enrichment (raised basking platforms) on the natural ecology of eastern fence lizards (Sceloporus undulatus), Rosier and Langkilde [52] found that this form of enrichment did not affect activity levels.

Reducing abnormal behaviors is a common goal in animal enrichment, but a lack of undesirable behaviors does not mean the animal is thriving in captivity [14,24]. Behavioral diversity is commonly used to evidence an increase in a wide range of behaviors. However, even this is not without its issues, in that while increasing behavioral diversity can be another aim of enrichment, it is not always a good measure of success, as if the enrichment results in the development of a new abnormal behavior, this will increase behavioral diversity [53]. Appropriate evaluation of enrichment programs is essential so that if the intended goals are not met, alternative strategies can be devised [20,52,54]. Furthermore, within enrichment research, it is vital that researchers report nonsignificant results [23,32], as enrichment that is ineffective does little to improve welfare and is not time- nor costeffective [55], with time being the largest limiting factor of enrichment provision among keepers [10]. Following frameworks such as the SPIDER framework to Set goals, Plan, Implement, Document, Evaluate, and Readjust if needed ensures that any enrichment offered is maximizing benefits to the individual [20]. The goals and enrichment plans should consider the animal's natural biology and ecology to be species-specific and relevant for the intended recipient.

\section{Is Enrichment Vital for Varanids?}

\subsection{A Brief Background of Varanidae}

Native to Africa, Asia, and Australasia [56], there are currently 83 known species of this monotypic family, with the only extant genus Varanus [57]. Of these 83, at least 50 are known to have been kept in captivity [58]. Many of these are also popular pet species, and with the global population of exotic reptile pets increasing and considering CITES trade statistics, there are likely to be several thousand individuals in captivity around the world $[59,60]$. In the wild, varanids (commonly called 'monitor lizards') occupy a diverse range of habitats and niches, in which some are terrestrial, others are aquatic or semi-aquatic, arboreal, or semi-arboreal, and some are saxicolous (rock-dwelling) [61]. Many of these lizards are active predatory species, typically being opportunistic generalists, except for the three known frugivorous species-V. mabitang, V. olivaceus, and $V$. bitatawa, of the Philippines $[62,63]$. Despite this variety, monitors are conservative in 
their morphology, but vary greatly in size [61]. Unlike most reptiles, these lizards are relatively energy-efficient [64], capable of sustaining high metabolic rates and prolonged high-speed movement $[65,66]$. This is due to their complex lungs that are reminiscent of avian lungs [67] in their unidirectional airflow [68], as well as their gular pump that allows them to breathe while running (unlike other lizards) $[65,69]$, in addition to a high $\mathrm{VO}_{2}$ max and morphological specializations to the heart and skeletal muscles [69]. Varanids are reputed to be the most intelligent of all lizards and possess a telencephalon (the most highly developed part of the forebrain) that constitutes a larger proportion of their relative brain size in comparison to other lizards [70,71]. These features are in part why the Varanus body plan has been so successful [61] and why these lizards would benefit greatly from enrichment, particularly as they are prone to obesity in captivity and require adequate exercise [56]. This is a particular conundrum as varanids are often kept in enclosures that spatially are a fraction of their natural home ranges [72].

\subsection{Cognitive Abilities}

Cognitive skills are the process that animals acquire, handle, and store information from the environment, and their cognitive abilities refer to the ways that they can act upon this information [73]. The varanid's higher intelligence has long been recognized [74-76], along with their curiosity, perceptiveness, apparent ability to recognize different keepers $[56,61]$, and ability to be successfully target trained [32,77]. Experiments carried out on captive $V$. albigularis even suggest that they may have counting-like skills as they appeared to be able to count to six [78], which is theorized to be attributed to raiding the nests of other reptiles, birds, and mammals, given that the average clutch or litter size would be around six [61]. The 'allostasis concept' argues that animals are adapted to respond to challenge and therefore require cognitive skills to function normally [79]. The wild environment is in stark contrast to the highly predictable environment faced by captive animals [4]. Despite the requirement of wild animals to employ behavioral strategies and cognitive abilities to solve problems (such as the need to access and control limited resources) in ways that minimize threat to self, cognitive challenge is an under-utilized method of enrichment [80]. With any cognitive enrichment, however, the cognitive challenge provided must be appropriate to that animal. If a task fails to challenge an individual animal, either boredom or apathy may result, the state dependent on the cognitive skills of the animal (high or low, respectively) [80]. Alternatively, opportunities that challenge an individual that does not have the appropriate skills to meet the tasks demands can result in anxiety [81]. When the task is well matched to the individuals' skills, it results in the individual becoming absorbed in the task, as well as the experience of pleasure and satisfaction referred to as flow [82]. The flow model is useful in enrichment development [80] but has yet to be applied as these emotional states (boredom, apathy, anxiety, and pleasure) are difficult to measure [4]. Additionally, the animals' cognitive abilities and the way in which they perceive the world must first be understood, a difficult task to perform through a human-centered perspective [22] As a result, studies investigating animal cognition have typically focused on non-human primates and, to a lesser extent, marine mammals [4].

The cognitive abilities of monitor lizards have been studied a handful of times, concluding that this genus is capable of problem solving and rapid learning [75,83-85], as well as reversal learning [86] and procedural learning [76]. Considering their biology and ecology, varanids, with excellent eyesight and active predatory foraging ability, would be expected to learn and respond to visual stimuli. This was successfully demonstrated with rough-necked monitors ( $V$. rudicollis) who were able to discriminate between colors of stimuli as well as showing reverse learning when retrained with different stimuli [86]. Unpalatability of certain prey species (a selective advantage for that prey species as a whole, as predators learn to avoid them in future), means that the taste senses of varanids should also be well established. Indeed, evidence of this is reported through toxic prey avoidance learning in the floodplain monitor ( $V$. panoptes) [87]; thus, in addition to visual stimuli, gustatory stimuli should also be able to be discriminated. 
Learning is vital to conserve behavioral adaptations and cognitive function that can help individuals to thrive in captivity. The animal's ability to solve problems and retain this skill over time is one way to measure the success of the learning trail. Decreasing latencies to solve a cognitive task suggests that black-throated monitors ( $V$. albigularis) can become more efficient at solving food-based puzzles by reducing unnecessary behaviors that do not result in success [85]. Cooper et al. [75] found evidence of problem solving using puzzle feeders in three species of monitor lizards - V. rudicollis, $V$. prasinus, and V. mertensi. In a follow-up study, evidence of long-term procedural learning ability was documented in that Varanus prasinus and Varanus mertensi that were quicker to solve the same puzzle a year later than when they first encounter the task [76].

Given that varanids have the longest incubation period of any lizard, a trait hypothesized to be attributed to their increased brain size [88], the effects of breeding environments should be taken into consideration when assessing cognitive abilities and further, as part of optimal husbandry, to maintain cognitive abilities in the next generation. In particular, the effect of incubation temperature on cognitive abilities should be considered as hatchling velvet geckos (Amalosia lesueurii) from 'hot-incubated' eggs (nest temperatures that could be experienced by $A$. lesueurii in the year 2050 [89]: mean $=27^{\circ} \mathrm{C}$, range $14-37^{\circ} \mathrm{C}$ ) had slower spatial learning abilities than hatchlings from 'cold-incubated' eggs (current nest temperatures: mean $=23.2{ }^{\circ} \mathrm{C}$, range $\left.10-33{ }^{\circ} \mathrm{C}\right)[90,91]$. Another factor that could be important to consider is social learning abilities. Many lizards are considered 'nonsocial', and even amongst the more social species, this can often be of a temporary nature [50]. However, research is beginning to identify instances of social learning in reptiles [92,93], and while there has been nothing published yet on the varanids, there are many instances of social behaviors (including play behavior) that suggest that social learning is possible.

\subsection{Play Behaviour}

The tendency of animals to play has been linked with brain size [94] and regarded to be a mode of information acquisition. 'True play' was initially considered a trait only exhibited by mammals and birds; Burghardt [38], however, reports of play in Komodo dragons ( $V$. komodoensis) going back over 80 years. More recently, blue-spotted tree monitors (V. macraei) and green tree monitors (V. prasinus) [77] have been observed to exhibit play behavior that meets the following five criteria of play developed by Burghardt [38]: (1) a behavior that is not fully functional in the context or form in which it is expressed; (2) a behavior that is voluntary, spontaneous, intentional, pleasurable, rewarding, reinforcing, or autotelic; (3) a behavior that differs structurally or temporally from strictly functional behaviors; (4) a behavior that is performed repeatedly in a similar, but not rigidly stereotyped, form; (5) a behavior that is performed when an animal is in a relaxed, unstimulating, or low-stress environment. These tree monitors, housed at two separate collections (V. macraei at ZSL London Zoo and V. prasinus at Bristol Zoo), were both observed participating in the same object-based play behavior with live plants in the enclosure [77]. This behavior, not observed in wild animals, resembles natural prey-tearing and wiping behavior [95] and may have developed through under-stimulation, as animals may seek to create their own diversions in the absence of extrinsic ones [77]. Alternatively, play may arise when there is minimal stress and sufficient resources to allow time for other behaviors, a theory proposed as the Surplus Resource Theory [96]. In addition to reports of play in captive varanids, a wild yellow monitor ( $V$. flavescens) was recently observed vertical swimming in a forward/backward motion in what was perceived to be play [97]. If monitor lizards play, it is an added incentive to provide enrichment [32] that promotes these behaviors, particularly as such behaviors tend to be motivationally robust and do not readily habituate [38]. However, again, adequate enrichment must be facilitated by provision of adequate space [72]. 


\section{Future Directions for Research}

Having considered the physiological and cognitive capabilities of monitor lizards, we find that there is a clear need for enhanced provision of enrichment for this family group. They possess a metabolism that is said to 'bridge the gap' between reptiles and mammals [98], they exhibit 'mammal-like' feeding behavior [95], and their cognitive abilities have suggested that they could be regarded as the 'primate of the squamate world' $[77,96]$. Yet, to the authors knowledge, there have been no empirical studies carried out regarding varanid enrichment or its efficacy, except for one quasi-experimental study by Mendyk and Horn [74]. Two adult black tree monitors (V. beccarii), kept as part of Mendyk's private collection, were observed exhibiting skilled forelimb movements to retrieve food through a small gap. Following these observations, a series of four holes narrower than the width of the monitors' heads were drilled into two tree trunks, which were then filled with a variety of prey items. Using coordinated forearm movements, both subjects successfully retrieved all prey types from all four holes located in each tree trunk. Furthermore, despite being housed in separate enclosures, both individuals used identical extraction behaviors. Thus, Mendyk and Horn [74] suspect this behavior to be instinctive. These results were also replicated in an additional female $V$. beccarii kept by another keeper upon request of the authors. Furthermore, all subjects involved continued to show interest in the drilled tree trunk holes. This behavior requires high levels of processing skills, motor coordination, and dexterity, yet again suggesting that varanids share many biological similarities with mammals [74]. Similar extractive behaviors have been observed in other varanid species. The Kimberley rock monitor ( $V$. glauerti) will use its claws to widen the diameter of the opening until it is large enough for the head to enter [99], while the sand goanna ( $V$. gouldii) will use its tail to flush out prey from rock crevices [100]. These differences may possibly be the result of differences in claw morphometrics [101]. Thus, the efficacy of different types of puzzle feeders as enrichment devices may vary between varanid species, again highlighting the importance of enrichment evaluation. Referring back to the five enrichment categories (which are not mutually exclusive), monitor lizards would likely benefit from puzzle feeders as a means of providing nutritional and occupational enrichment, and these may be made part of the enclosure (such as the drilled tree trunks) as a means of physical enrichment, so long as they are relevant to the species' natural ecology. However, it is important to remember that these can become physical rather than cognitive barriers to food acquisition [80], and with the learning abilities of varanids, it is likely that such devices would need to be modified and updated regularly [80]. The effectiveness of enrichment methods can also be maintained through practices such as the use of partial reinforcement schedules [55].

As demonstrated by Mendyk and Horn [74], case studies that document novel behaviors in captivity, as well as those behaviors observed in wild individuals [99,100], can inform the goals for future captive enrichment programs. For example, recently reported was a rolling prey capture behavior in V. albigularis, comparable to the 'death roll' of crocodilians, whereby the animal grips a food item with its jaws and spins on their longitudinal axis with their four limbs pressed to their body [102]. Additionally, social enrichment and cognition research is needed. For varanids, whose social behavior is also highly scent-orientated [56], this would likely require a combination with sensory enrichment via the scent of conspecifics, with scent being their most acute sense, thanks to their deeply forked tongue and Jacobson's organ. These are just some suggestions based upon natural ecology and the findings of this review. New enrichment ideas are typically based upon previously reported successes [10], and with such a large gap in the peer-reviewed literature, anecdotes from monitor lizard keepers are the place to start [32]. While keepers may not accurately perceive the effectiveness of their enrichment provision, it can provide a basis for enrichment creation that can be empirically evaluated. Furthermore, it would provide an insight into how keepers attempt to tackle the constraints of time, cost, and space, and whether they account for the diversity between varanid species when considering enrichment provision. 
Given that the ultimate goal of enrichment is typically to improve the welfare of captive animals, we must also focus on the ways in which we assess welfare. Historically, the presence or absence of stereotypical and/or abnormal repetitive behaviors has been a leading indicator of animal welfare; however, the past experience of individual animals can make this an unreliable indicator. If such a behavior undergoes a process of 'establishment', whereby it becomes disassociated from the individual's current welfare [103], then it can appear to be enrichment-resistant, and thus an unreliable indicator of the individual's current welfare [104]. Consequently, further research is needed to develop the use of 'affective states' as a welfare indicator. While an animal's affective state cannot be measured directly, it can be conducted experimentally using cognitive bias testing [4]. This method requires the animal to be trained to discriminate between different stimuli, of which varanids are capable $[84,86]$. Thus, this would likely prove to be a valuable area of future research. Additionally, future research may also investigate the effectiveness of using the flow model in varanids, beginning with whether the emotional states of flow, boredom, apathy, and anxiety can be accurately measured in this family of lizards. Methods may include measuring levels of motivation, such as willingness to exert high-effort for a highvalue reward as a means of measuring apathy [105]; measuring levels of interest, such as the time-oriented to and in contact with multiple stimuli as a means of measuring boredom [106]; measuring absorption in a task, such as how easily and animal is distracted from a task as a means to measure flow [107]; or measuring exploratory behavior, such as in an elevated plus maze as a means of measuring anxiety [108]. However, it must be noted that these measures are based on mammalian studies, and as such, may not translate to use in varanids.

\section{Conclusions}

It has been over 25 years since Bennett [56] stated that monitor lizards have not been given the attention they deserve, and from the current review, this statement appears to hold true. There is growing evidence that enrichment is beneficial to reptiles and that this should be integral to their care and not just an additional luxury. Their cognition and behavioral flexibility are arguably comparative to that of mammals. Given the impressive cognitive abilities of varanids, as well as their propensity for play, it is likely that they are susceptible to boredom as a result of an unstimulating environment. Research that documents training programs with such species is needed to help inform evidence-based practice and this should include training for reintroductions and translocations. More cognitive studies are needed on varanids to continue to explore the extent of their abilities, including social learning and the extent that social enrichment is needed and to investigate cognitive enrichment that challenges and provides an opportunity to learn new skills that help them cope with the environment. Furthermore, future research is needed to investigate whether the affective states of varanids can be accurately measured in order to provide an additional means of assessing welfare, thus aiding in enrichment evaluation. If these lizards are to be provided with a high quality of life, then they should be provided with appropriate enrichment. This starts with the empirical evaluation of anecdotal methods that have been reported to be successful by varanid keepers. However, it is essential that any subsequent behaviors that are elicited are recognized as those generated within conditions of captivity, and these should never undermine any thorough investigation of species-specific varanid behavior in the wild [72].

Author Contributions: Conceptualization, D.H.; writing—original draft preparation, D.H. and M.S.F.; writing-review and editing, D.H. and M.S.F. All Authors have read and agreed to the published version of the manuscript.

Funding: This research received no external funding.

Institutional Review Board Statement: Not applicable.

Informed Consent Statement: Not applicable. 
Data Availability Statement: Data sharing not applicable.

Conflicts of Interest: The authors declare no conflict of interest.

\section{References}

1. Rees, P.A. An Introduction to Zoo Biology and Management; John Wiley \& Sons: Hoboken, NJ, USA, 2011.

2. Markowitz, H. Engineering Environments for Behavioral Opportunities in the Zoo. Behav. Anal. 1978, 1, 34-47. [CrossRef] [PubMed]

3. Fernandez, E.J.; Martin, A.L. Animal Training, Environmental Enrichment, and Animal Welfare: A History of Behavior Analysis in Zoos. J. Zool. Bot. Gard. 2021, 2, 531. [CrossRef]

4. Clark, F.E. Cognitive Enrichment and Welfare: Current Approaches and Future Directions. Anim. Behav. Cognit. 2017, 4, 52-71. [CrossRef]

5. Riley, L.M.; Rose, P.E. Concepts, Applications, Uses and Evaluation of Environmental Enrichment: Perceptions of Zoo Professionals. J. Zoo Aquar. Res. 2020, 8, 18-28.

6. Banton-Jones, K. Why Enrichment Isn't an Extra. Available online: www.wildenrichment.com (accessed on 11 July 2021).

7. Shepherdson, D.J. Tracing the Path of Environmental Enrichment in Zoos. In Second Nature: Environmental Enrichment for Captive Animals; Shepherdson, D., Mellen, J.D., Hutchins, M., Eds.; Smithsonian Institution Press: Washington, DC, USA, 1998 ; pp. 1-12.

8. Buchanan-Smith, H.M. Environmental Enrichment for Primates in Laboratories. Adv. Sci. Res. 2011, 5, 41-56. [CrossRef]

9. Bloomsmith, M.A.; Brent, L.Y.; Schapiro, S.J. Guidelines for Developing and Managing an Environmental Enrichment Program for Nonhuman Primates. Lab. Anim. Sci. 1991, 41, 372-377. [PubMed]

10. Hoy, J.M.; Murray, P.J.; Tribe, A. Thirty Years Later: Enrichment Practices for Captive Mammals. Zoo Biol. 2010, 29 , 303-316. [CrossRef] [PubMed]

11. Skibiel, A.L.; Trevino, H.S.; Naugher, K. Comparison of Several Types of Enrichment for Captive Felids. Zoo Biol. 2007, 26, 371-381. [CrossRef] [PubMed]

12. Mellen, J.; Sevenich MacPhee, M. Philosophy of Environmental Enrichment: Past, Present, and Future. Zoo Biol. 2001, 20, 211-226. [CrossRef]

13. Mason, G.; Clubb, R.; Latham, N.; Vickery, S. Why and How Should We Use Environmental Enrichment to Tackle Stereotypic Behaviour? Appl. Anim. Behav. Sci. 2007, 102, 163-188. [CrossRef]

14. Melfi, V.A. There Are Big Gaps in Our Knowledge, and Thus Approach, to Zoo Animal Welfare: A Case for Evidence-Based Zoo Animal Management. Zoo Biol. 2009, 28, 574-588. [CrossRef] [PubMed]

15. Rose, P.E.; Brereton, J.E.; Rowden, L.J.; de Figueiredo, R.L.; Riley, L.M. What's New from the Zoo? An Analysis of Ten Years of Zoo-Themed Research Output. Palgrave Commun 2019, 5, 1-10.

16. Swaisgood, R.R. Current Status and Future Directions of Applied Behavioral Research for Animal Welfare and Conservation. Appl. Anim. Behav. Sci. 2007, 102, 139-162. [CrossRef]

17. Eagan, T. Evaluation of Enrichment for Reptiles in Zoos. J. Appl. Anim. Welf. Sci. 2019, 22, 69-77. [CrossRef]

18. De Azevedo, C.S.; Cipreste, C.F.; Young, R.J. Environmental Enrichment: A GAP Analysis. Appl. Anim. Behav. Sci. 2007, 102, 329-343. [CrossRef]

19. Maple, T.L.; Perdue, B.M. Environmental Enrichment. In Zoo Animal Welfare; Springer: Berlin/Heidelberg, Germany, 2013; pp. 95-117.

20. Alligood, C.; Leighty, K. Putting the "E" in SPIDER: Evolving Trends in the Evaluation of Environmental Enrichment Efficacy in Zoological Settings. Anim. Behav. Cogn. 2015, 2, 200-217. [CrossRef]

21. Case, B.C.; Lewbart, G.A.; Doerr, P.D. The Physiological and Behavioural Impacts of and Preference for an Enriched Environment in the Eastern Box Turtle (Terrapene carolina carolina). Appl. Anim. Behav. Sci. 2005, 92, 353-365. [CrossRef]

22. Doody, J.S.; Burghardt, G.M.; Dinets, V. Breaking the Social-Non-Social Dichotomy: A Role for Reptiles in Vertebrate Social Behavior Research? Ethology 2013, 119, 95-103. [CrossRef]

23. Learmonth, M.J. The Matter of Non-Avian Reptile Sentience, and Why It "Matters" to Them: A Conceptual, Ethical and Scientific Review. Animals 2020, 10, 901. [CrossRef]

24. Warwick, C.; Arena, P.; Lindley, S.; Jessop, M.; Steedman, C. Assessing Reptile Welfare Using Behavioural Criteria. InPractice 2013, 35, 123-131. [CrossRef]

25. Roth, T.C.; Krochmal, A.R.; LaDage, L.D. Reptilian Cognition: A More Complex Picture via Integration of Neurological Mechanisms, Behavioral Constraints, and Evolutionary Context. BioEssays 2019, 41, 1900033. [CrossRef]

26. Burghardt, G.M.; Ward, B.; Rosscoe, R. Problem of Reptile Play: Environmental Enrichment and Play Behavior in a Captive Nile Soft-Shelled Turtle, Trionyx Triunguis. Zoo Biol. 1996, 15, 223-238. [CrossRef]

27. Londoño, C.; Bartolomé, A.; Carazo, P.; Font, E. Chemosensory Enrichment as a Simple and Effective Way to Improve the Welfare of Captive Lizards. Ethology 2018, 124, 674-683. [CrossRef]

28. Almli, L.M.; Burghardt, G.M. Environmental Enrichment Alters the Behavioral Profile of Ratsnakes (Elaphe). J. Appl. Anim. Welf. Sci. 2006, 9, 85-109. [CrossRef]

29. Therrien, C.L.; Gaster, L.; Cunningham-Smith, P.; Manire, C.A. Experimental Evaluation of Environmental Enrichment of Sea Turtles. Zoo Biol. 2007, 26, 407-416. [CrossRef] 
30. Passos, L.F.; Garcia, G.; Young, R. How Does Captivity Affect Skin Colour Reflectance of Golden Mantella Frogs? Herpetol. J. 2020, 30, 13-19. [CrossRef]

31. Bashaw, M.J.; Gibson, M.D.; Schowe, D.M.; Kucher, A.S. Does Enrichment Improve Reptile Welfare? Leopard Geckos (Eublepharis macularius) Respond to Five Types of Environmental Enrichment. Appl. Anim. Behav. Sci. 2016, 184, 150-160.

32. Burghardt, G.M. Environmental Enrichment and Cognitive Complexity in Reptiles and Amphibians: Concepts, Review, and Implications for Captive Populations. Appl. Anim. Behav. Sci. 2013, 147, 286-298. [CrossRef]

33. Rose, P.; Evans, C.; Coffin, R.; Miller, R.; Nash, S. Using Student-Centred Research to Evidence-Base Exhibition of Reptiles and Amphibians: Three Species-Specific Case Studies. J. Zoo Aquar. Res. 2014, 2, 25-32.

34. Hoehfurtner, T.; Wilkinson, A.; Nagabaskaran, G.; Burman, O.H.P. Does the Provision of Environmental Enrichment Affect the Behaviour and Welfare of Captive Snakes? Appl. Anim. Behav. Sci. 2021, 239, 105324. [CrossRef]

35. Bannister, C.C.; Thomson, A.J.C.; Cuculescu-Santana, M. Can Colored Object Enrichment Reduce the Escape Behavior of Captive Freshwater Turtles? Zoo Biol. 2021, 40, 160-168. [CrossRef]

36. Swaisgood, R.R.; Shepherdson, D.J. Scientific Approaches to Enrichment and Stereotypies in Zoo Animals: What's Been Done and Where Should We Go Next? Zoo Biol. 2005, 24, 499-518. [CrossRef]

37. Saudargas, R.A.; Drummer, L.C. Single Subject (Small N) Research Designs and Zoo Research; Wiley: Hoboken, NJ, USA, 1996.

38. Burghardt, G.M. A Brief Glimpse at the Long Evolutionary History of Play. Anim. Behav. Cogn. 2014, 1, 90-98. [CrossRef]

39. Januszczak, I.S.; Bryant, Z.; Tapley, B.; Gill, I.; Harding, L.; Michaels, C.J. s Behavioural Enrichment Always a Success? Comparing Food Presentation Strategies in an Insectivorous Lizard (Plica plica). Appl. Anim. Behav. Sci. 2016, 183, 95-103. [CrossRef]

40. Kanaan, V.T.; Hötzel, M.J. Does Environmental Enrichment Really Matter? A Case Study Using the Eastern Fence Lizard, Sceloporus Undulatus. Appl. Anim. Behav. Sci. 2011, 135, 169-170. [CrossRef]

41. Izzo, G.N.; Bashaw, M.J.; Campbell, J.B. Enrichment and Individual Differences Affect Welfare Indicators in Squirrel Monkeys (Saimiri sciureus). J. Comp. Psychol. 2011, 125, 347. [CrossRef]

42. Alligood, C.A.; Dorey, N.R.; Mehrkam, L.R.; Leighty, K.A. Applying Behavior-Analytic Methodology to the Science and Practice of Environmental Enrichment in Zoos and Aquariums. Zoo Biol. 2017, 36, 175-185. [CrossRef]

43. Learmonth, M.J.; Sherwen, S.; Hemsworth, P.H. Assessing Preferences of Two Zoo-Housed Aldabran Giant Tortoises (Aldabrachelys gigantea) for Three Stimuli Using a Novel Preference Test. Zoo Biol. 2021, 40, 98-106. [CrossRef] [PubMed]

44. Wilkinson, A.; Huber, L. Cold-Blooded Cognition: Reptilian Cognitive Abilities. In The Oxford Handbook of Comparative Evolutionary Psychology; Oxford University Press: Oxford, UK, 2012; pp. 129-141.

45. Reading, R.P.; Miller, B.; Shepherdson, D. The Value of Enrichment to Reintroduction Success. Zoo Biol. 2013, 32, 332-341. [CrossRef]

46. Westlund, K. Training Is Enrichment-And Beyond. Appl. Anim. Behav. Sci. 2014, 152, 1-6. [CrossRef]

47. Degregorio, B.; Sperry, J.; Tuberville, T.; Weatherhead, P. Translocating Ratsnakes: Does Enrichment Offset Negative Effects of Time in Captivity? Wildl. Res. 2017, 44. [CrossRef]

48. Roe, J.H.; Frank, M.R.; Kingsbury, B.A. Experimental Evaluation of Captive-Rearing Practices to Improve Success of Snake Reintroductions. Herpetol. Conserv. Biol. 2015, 10, 711-722.

49. Roth, T.C.; Krochmal, A.R. The Role of Age-Specific Learning and Experience for Turtles Navigating a Changing Landscape. Curr. Biol. 2015, 25, 333-337. [CrossRef]

50. Meester, G.D.; Baeckens, S. Reinstating Reptiles: From Clueless Creatures to Esteemed Models of Cognitive Biology. Behaviour 2021, 158, 1057-1076. [CrossRef]

51. Mehrkam, L.R.; Dorey, N.R. Preference Assessments in the Zoo: Keeper and Staff Predictions of Enrichment Preferences across Species. Zoo Biol. 2015, 34, 418-430. [CrossRef]

52. Rosier, R.L.; Langkilde, T. Does Environmental Enrichment Really Matter? A Case Study Using the Eastern Fence Lizard, Sceloporus Undulatus. Appl. Anim. Behav. Sci. 2011, 131, 71-76. [CrossRef]

53. Cronin, K.; Ross, S. Technical Contribution: A Cautionary Note on the Use of Behavioural Diversity (H-Index) in Animal Welfare Science. Anim. Welf. 2019, 28, 157-164. [CrossRef]

54. Rosier, R.L.; Langkilde, T.L. In Response to the Letter to the Editor Regarding the Article: “Does Environmental Enrichment Really Matter? A Case Study Using the Eastern Fence Lizard, Sceloporus Undulatus". Appl. Anim. Behav. Sci. 2011, 135, 171-172. [CrossRef]

55. Tarou, L.R.; Bashaw, M.J. Maximizing the Effectiveness of Environmental Enrichment: Suggestions from the Experimental Analysis of Behavior. Appl. Anim. Behav. Sci. 2007, 102, 189-204. [CrossRef]

56. Bennett, D. A Little Book of Monitor Lizards: A Guide to the Monitor Lizards of the World and Their Care in Captivity; Viper Press: Aberdeen, UK, 1995.

57. Uetz, P.; Freed, P.; Hošek, J. The Reptile Database. Available online: https://reptile-database.reptarium.cz/ (accessed on 11 July 2021).

58. Ziegler, T.; Rauhaus, A.; Gill, I. A Preliminary Review of Monitor Lizards in Zoological Gardens. Biawak 2016, 10 , $26-35$.

59. Valdez, J.W. Using Google Trends to Determine Current, Past, and Future Trends in the Reptile Pet Trade. Animals 2021, 11, 676. [CrossRef]

60. CITES. CITES Trade Database; UNEP World Conservation Monitoring Centre: Cambridge, UK, 2021.

61. Pianka, E.; King, D. Varanoid Lizards of the World; Indiana University Press: Bloomington, IN, USA, 2004. 
62. Welton, L.J.; Siler, C.D.; Bennett, D.; Diesmos, A.; Duya, M.R.; Dugay, R.; Rico, E.L.B.; Van Weerd, M.; Brown, R.M. A Spectacular New Philippine Monitor Lizard Reveals a Hidden Biogeographic Boundary and a Novel Flagship Species for Conservation. Biol. Lett. 2010, 6, 654-658. [CrossRef] [PubMed]

63. Law, S.J.; de Kort, S.R.; Bennett, D.; van Weerd, M. Diet and Habitat Requirements of the Philippine Endemic Frugivorous Monitor Lizard Varanus Bitatawa. Biawak 2018, 12, 12-22.

64. Dryden, G.; Green, B.; King, D.; Losos, J. Water and Energy Turnover in a Small Monitor Lizard, Varanus-Acanthurus. Wildl. Res. 1990, 17, 641-646. [CrossRef]

65. Frappell, P.B.; Schultz, T.J.; Christian, K.A. The Respiratory System in Varanid Lizards: Determinants of $\mathrm{O}_{2}$ Transfer. Comp Biochem. Physiol. Part A Mol. Integr. Physiol. 2002, 133, 239-258. [CrossRef]

66. Cross, S.L.; Craig, M.D.; Tomlinson, S.; Bateman, P.W. I Don't like Crickets, I Love Them: Invertebrates Are an Important Prey Source for Varanid Lizards. J. Zool. 2020, 310, 323-333. [CrossRef]

67. Cieri, R.L.; Farmer, C.G. Computational Fluid Dynamics Reveals a Unique Net Unidirectional Pattern of Pulmonary Airflow in the Savannah Monitor Lizard (Varanus exanthematicus). Anat. Rec. 2020, 303, 1768-1791. [CrossRef] [PubMed]

68. Schachner, E.R.; Cieri, R.L.; Butler, J.P.; Farmer, C.G. Unidirectional Pulmonary Airflow Patterns in the Savannah Monitor Lizard. Nature 2014, 506, 367-370. [CrossRef] [PubMed]

69. Clemente, C.J.; Withers, P.C.; Thompson, G.G. Metabolic Rate and Endurance Capacity in Australian Varanid Lizards (Squamata: Varanidae: Varanus). Biol. J. Linn. Soc. 2009, 97, 664-676. [CrossRef]

70. Northcutt, R.G. Variation in Reptilian Brains and Cognition. Brain Behav. Evol. 2013, 82, 45-54. [CrossRef] [PubMed]

71. Güntürkün, O.; Stacho, M.; Ströckens, F. The Brains of Reptiles and Birds. Evol. Neurosci. 2020, 159-212.

72. Arena, P.; Warwick, C. Spatial and Thermal Considerations. In Health and Welfare of Captive Reptiles; Animal Welfare Series; Springer: Cham, Switzerland, 2022; Volume 22.

73. Shettleworth, S.J. Animal Cognition and Animal Behaviour. Anim. Behav. 2001, 61, 277-286. [CrossRef]

74. Mendyk, R.W.; Horn, H.G. Skilled Forelimb Movements and Extractive Foraging in the Arboreal Monitor Lizard Varanus Beccarii (Doria, 1874). Herpetol. Rev. 2011, 42, 343-349.

75. Cooper, T.; Liew, A.; Andrle, G.; Cafritz, E.; Dallas, H.; Niesen, T.; Slater, E.; Stockert, J.; Vold, T.; Young, M. Latency in Problem Solving as Evidence for Learning in Varanid and Helodermatid Lizards, with Comments on Foraging Techniques. Copeia 2019, 107, 78-84. [CrossRef]

76. Cooper, T.L.; Zabinski, C.L.; Adams, E.J.; Berry, S.M.; Pardo-Sanchez, J.; Reinhardt, E.M.; Roberts, K.M.; Watzek, J.; Brosnan, S.F.; Hill, R.L. Long-Term Memory of a Complex Foraging Task in Monitor Lizards (Reptilia: Squamata: Varanidae). J. Herpetol. 2020, 54, 378-383. [CrossRef]

77. Kane, D.; Davis, A.C.; Michaels, C.J. Play Behaviour by Captive Tree Monitors, Varanus Macraei and Varanus Prasinus. Herpetol. Bull. 2019, 149, 28-31. [CrossRef]

78. King, D.; Green, B. Goannas: The Biology of Varanid Lizards; UNSW Press: Kensington, Australia, 1999.

79. Korte, S.M.; Olivier, B.; Koolhaas, J.M. A New Animal Welfare Concept Based on Allostasis. Physiol. Behav. 2007, 92, 422-428. [CrossRef] [PubMed]

80. Meehan, C.L.; Mench, J.A. The Challenge of Challenge: Can Problem Solving Opportunities Enhance Animal Welfare? Appl. Anim. Behav. Sci. 2007, 102, 246-261. [CrossRef]

81. Myers, D.G.; Diener, E. Who Is Happy? Psychol. Sci. 1995, 6, 10-19. [CrossRef]

82. Nakamura, J.; Csikszentmihalyi, M. The Concept of Flow. In Flow and the Foundations of Positive Psychology; Springer: Berlin/Heidelberg, Germany, 2014; pp. 239-263.

83. Loop, M.S. Auto-Shaping: A Simple Technique for Teaching a Lizard to Perform a Visual Discrimination Task. Copeia 1976, 1976, 574-576. [CrossRef]

84. Firth, I.; Turner, M.; Robinson, M.; Meek, R. Response of Monitor Lizards (Varanus spp. ) to a Repeated Food Source: Evidence for Association Learning? Herpetol. Bull. 2003, 84, 1-4.

85. Manrod, J.D.; Hartdegen, R.; Burghardt, G.M. Rapid Solving of a Problem Apparatus by Juvenile Black-Throated Monitor Lizards (Varanus albigularis albigularis). Anim. Cognit. 2008, 11, 267-273. [CrossRef]

86. Gaalema, D.E. Visual Discrimination and Reversal Learning in Rough-Necked Monitor Lizards (Varanus rudicollis). J. Comp. Psychol. 2011, 125, 246-249. [CrossRef] [PubMed]

87. Ward-Fear, G.; Thomas, J.; Webb, J.K.; Pearson, D.J.; Shine, R. Eliciting Conditioned Taste Aversion in Lizards: Live Toxic Prey Are More Effective than Scent and Taste Cues Alone. Integr. Zool. 2017, 12, 112-120. [CrossRef]

88. Andrews, R.M.; Pezaro, N.; Doody, J.S.; Guarino, F.; Green, B. Oviposition to Hatching: Development of Varanus Rosenbergi. J. Herpetol. 2017, 51, 396-401. [CrossRef]

89. Watterson, I.; Abbs, D.; Bhend, J.; Chiew, F.; Church, J.; Ekström, M.; Kirono, D.; Lenton, A.; Lucas, C.; McInnes, K. Climate Change in Australia Projections for Australia's Natural Resource Management Regions; CSIRO: Canberra, Australia, 2015.

90. Dayananda, B.; Webb, J.K. Incubation under Climate Warming Affects Learning Ability and Survival in Hatchling Lizards. Biol. Lett. 2017, 13, 20170002. [CrossRef] [PubMed]

91. Abayarathna, T.; Webb, J.K. Effects of Incubation Temperatures on Learning Abilities of Hatchling Velvet Geckos. Anim. Cognit. 2020, 23, 613-620. [CrossRef] [PubMed] 
92. Kis, A.; Huber, L.; Wilkinson, A. Social Learning by Imitation in a Reptile (Pogona vitticeps). Anim. Cognit. 2015, 18, 325-331. [CrossRef] [PubMed]

93. Noble, D.W.; Byrne, R.W.; Whiting, M.J. Age-Dependent Social Learning in a Lizard. Biol. Lett. 2014, 10, 20140430. [CrossRef]

94. Iwaniuk, A.N.; Nelson, J.E.; Pellis, S.M. Do Big-Brained Animals Play More? Comparative Analyses of Play and Relative Brain Size in Mammals. J. Comp. Psychol. 2001, 115, 29-41. [CrossRef] [PubMed]

95. Stanner, M. Mammal-like Feeding Behavior of Varanus Salvator and Its Conservational Implications. Biawak $2010,4,128-131$.

96. Burghardt, G.M. The Genesis of Animal Play: Testing the Limits; MIT Press: Cambridge, MA, USA, 2005.

97. Khandakar, N.; Jeny, K.N.; Islam, S.; Hakim, M.A.; Pony, I.A. Play Behavior by a Yellow Monitor, Varanus Flavescens (Hardwicke and Gray 1827). Reptiles Amphib. 2020, 27, 257-258. [CrossRef]

98. Bartholomew, G.A.; Tucker, V.A. Size, Body Temperature, Thermal Conductance, Oxygen Consumption, and Heart Rate in Australian Varanid Lizards. Physiol. Zool. 1964, 37, 341-354. [CrossRef]

99. Sweet, S.S. Spatial Ecology of Varanus Glauerti and V. Glebopalma in Northern Australia. Mertensiella 1999, 11, $317-366$.

100. Eidenmüller, B. Bisher Nicht Beschriebene Verhaltensweisen von Varanus (Varanus) Flavirufus Mertens 1958, Varanus (Odatria) Acanthurus Boulenger 1885 Und Varanus (Odatria) Storri Mertens 1966 Im Terrarium. Monitor 1993, 2, 11-21.

101. D'Amore, D.C.; Clulow, S.; Doody, J.S.; Rhind, D.; McHenry, C.R. Claw Morphometrics in Monitor Lizards: Variable Substrate and Habitat Use Correlate to Shape Diversity within a Predator Guild. Ecol. Evol. 2018, 8, 6766-6778. [CrossRef]

102. Krebs, U.; Wünstel, U. Observations and Experiments on "Spinning Behavior" in Varanus Albigularis. Biawak $2019,13,54-61$.

103. Mason, G.J.; Latham, N. Can't Stop, Won't Stop: Is Stereotypy a Reliable Animal Welfare Indicator? Anim. Welf. 2004, 13, S57-S69.

104. Tilly, S.-L.C.; Dallaire, J.; Mason, G.J. Middle-Aged Mice with Enrichment-Resistant Stereotypic Behaviour Show Reduced Motivation for Enrichment. Anim. Behav. 2010, 80, 363-373. [CrossRef]

105. Jackson, M.G.; Lightman, S.L.; Gilmour, G.; Marston, H.; Robinson, E.S. Evidence for Deficits in Behavioural and Physiological Responses in Aged Mice Relevant to the Psychiatric Symptom of Apathy. Brain Neurosci. Adv. 2021, 5, 23982128211015110. [CrossRef] [PubMed]

106. Meagher, R. Is Boredom an Animal Welfare Concern? Anim. Welf. 2018, 28, 21-32. [CrossRef]

107. Clark, F.E. Great Ape Cognition and Captive Care: Can Cognitive Challenges Enhance Well-Being? Appl. Anim. Behav. Sci. 2011, 135, 1-12. [CrossRef]

108. Walf, A.A.; Frye, C.A. The Use of the Elevated plus Maze as an Assay of Anxiety-Related Behavior in Rodents. Nat. Protoc. 2007, 2, 322-328. [CrossRef] [PubMed] 